\title{
Particle Flux Effects on Physicochemical Polymer Degradations
}

\author{
S. Lewandowski* and S. Duzelier \\ ONERA - The French Aerospace Lab, F-31055 Toulouse, France \\ J. Eck $\$$ \\ TRAD, 31670 Labège, France \\ S. Dagras $\underline{\S}$ and C. Tonon! \\ Airbus Defence and Space, 31402 Toulouse CEDEX 4, France \\ H. Jochem $\stackrel{* *}{*}$ and P. Jouanne立 \\ Thales Alenia Space, 31037 Toulouse CEDEX 1, France \\ and \\ E. Laurent菨 and J. M. Desmarres $\underline{\underline{s}}$ \\ Centre National d'Études Spatiales, F-31401 Toulouse CEDEX 9, France
}

\begin{abstract}
DOI: $\underline{10.2514 / 1 . A 33500}$
Particle flux effects on polymer physicochemical degradations were investigated. Different polymers were studied depending on application: silicone, fluoropolymer, acrylic, epoxy, polyimide, polyurethane, etc. Polymers with surface functional properties (paint, coating, etc.) were dissociated from polymers with bulk properties (potting, cable, etc.). Surface materials were exposed to protons, and bulk materials were exposed to electron radiations. Two fluxes were used: $5 \times 10^{11}$ and $7.4 \times 10^{12} \mathrm{~cm}^{-2} \cdot \mathrm{s}^{-1}$ for electrons and $8.7 \times 10^{9}$ and $2.2 \times 10^{11} \mathrm{~cm}^{-2} \cdot \mathrm{s}^{-1}$ for protons. The total dose was fixed at $500 \mathrm{Mrad}$ for electron radiations and $1 \mathrm{Grad}$ for proton radiations. Functional properties (thermo-optical and mechanical) depending on material application were measured before and after irradiation exposure. Chemical structure modifications were also investigated. From all combined results, no global tendency was evidenced. The study shows that low or high irradiation flux induces more or less degradations according to polymer type, the composition of the polymer, and functional properties of concern. Flux effects can also depend on particle nature (electron or proton). The last point was highlighted by silicone polymer degradations; high proton flux caused more damage than low flux. On the contrary, low electron flux induced more degradations than high flux.
\end{abstract}

\section{Nomenclature}

$T_{g}=$ glass-transition temperature, ${ }^{\circ} \mathrm{C}$

$\alpha_{s}=$ solar absorptance

$\varepsilon_{\text {irr }}=$ infrared emissivity

\section{Introduction}

I N SPACE applications, materials are exposed to specific environments: charged particles (from the radiation belts), the solar spectrum, atomic oxygen (in low orbit, $<1000 \mathrm{~km}$ ), and micrometeorites and debris. Vacuum conditions and temperature are added to this.

Received 2 November 2015; revision received 24 May 2016; accepted for publication 9 June 2016; published online 26 August 2016. Copyright ( 2016 by the American Institute of Aeronautics and Astronautics, Inc. All rights reserved. Copies of this paper may be made for personal and internal use, on condition that the copier pay the per-copy fee to the Copyright Clearance Center (CCC). All requests for copying and permission to reprint should be submitted to CCC at www.copyright.com; employ the ISSN 0022-4650 (print) or 1533-6794 (online) to initiate your request.

*Scientist, Space Environment Department; simon.lewandowski@ onera.fr.

${ }^{\dagger}$ Scientist, Space Environment Department; sophie.duzelier@onera.fr.

†Scientist, Materials Radiation Division, Bâtiment Gallium, 907 Voie Occitane; julien.eck@trad.fr.

${ }^{\S}$ Engineer, Materials and Processes Division, 31 rue des cosmonautes; sabine.dagras@airbus.com.

†Technical Authority, Telecom Business Division, 31 rue des cosmonautes; claire.tonon@airbus.com.

**Scientist, Technological Department, 26 avenue J-F Champollion BP 33787; helene.jochem@ thalesaleniaspace.com.

${ }^{\dagger}$ Scientist, Technological Department, 26 avenue J-F Champollion BP 33787; pierre.jouanne@ thalesaleniaspace.com.

¥Scientist, Quality Assurance Division, 18 avenue Edouard Belin; elisabeth.laurent@cnes.fr.

${ }^{\S}$ Scientist, Quality Assurance Division, 18 avenue Edouard Belin; jean-michel.desmarres@cnes.fr.
Among these different environmental parameters, the charged particles are constituted by electrons or protons trapped in the radiation belts, rash protons (also $x$ rays on the sunny side) and solar wind. Materials on external parts of the satellite are directly exposed to this harsh environment. Charged particles mainly generate an ionizing absorbed dose profile into these materials. Because of their energy spectrum and the mode of interaction, the protons are responsible for the surface dose (first micrometers) and electrons for the bulk dose.

The interaction of particle radiation with an organic material causes the phenomena of chain scission and/or crosslinking via ionization mechanisms. The effects are linked to the accumulation over time of the ionizing dose (cumulative effect) causing surface and/or volume changes in the material. The induced macroscopic effects consist mainly of color change (absorbance increase and transmittance decrease) and the decrease of mechanical properties performance (mass loss, brittleness, reduced stress and strain at the break, etc.).

A classification of polymer materials by particle sensitivity and degradation type is given in the literature survey depending on polymer structures (e.g., the presence of the aromatic group leads to better stability) and the chemical composition of its monomer [1]]. Additives can also have a high influence on degradation. An index radiation indicator is given by Tavler et al. [European Laboratory for Particle Physics (CERN)] for prioritizing materials per family according to their mechanical behavior (ultimate strength and deformation) [2]. However, these classifications are based on data obtained under specific conditions, generally not representative of the space environment (data from nuclear industry or from neutrons and a gamma accelerator, with exposure to air). They only could be used as indicative.

Therefore, evaluation of material degradation during space missions is estimated by performing ground tests that closer simulate the space environment in order to select and qualify the appropriate materials [3]. For this, test facilities are used to replicate specific degrading components of the space environment. For many reasons, particularly to reduce the aging time and due to specifications of the particle accelerator, these tests are not performed under the exact same conditions as the environment the material will see over the 
lifetime of the mission. Accelerated tests, especially important for particle irradiation, are performed, according to specific standards [4-6]. The possible acceleration impact on the material degradation is currently not evaluated.

Dose rate effects have been observed in the literature, with potentially more degradation observed for low dose rates [7-9]. These dose rate effects may be due to the oxygen environment and the oxidation of radiolysis species created during irradiation. Again, many data come from nuclear applications (neutrons/in air) or CERN ( $\gamma$ and neutrons/in air). In this case, because of the oxygen involvement, surface effects are dominant, but low particle flux tests (for long durations) on thin layers can be critical to bulk properties. We can minimize the effect of oxygen by working under a stream of neutral gas (nitrogen and argon) or under vacuum, provided that there is no adsorbed oxygen. The effect of dose rates can be seen in vacuum particle irradiation. Briskman et al. report data on Polytetrafluoroethylene (PTFE) and low-density polyethylene [10], including the gas emission rate measurement, for which significant differences were observed for different dose rates. An increase of degradations of tensile strength and elongation at rupture was observed for PTFE at low dose rates. In contrast, Hardgrove presents other electrons $\left(e^{-}\right)+$protons $\left(p^{+}\right)$dose data at different acceleration rates that show for white paints that the worst case is observed at high acceleration rates [11]. A comparison with in-flight data leads him to the conclusion that the dose rate closest to space arrival provides the most realistic degradation value.

Considering these different results, the study presented in this paper aims to evaluate the particles flux effects on the physicochemical properties of different polymers. Indeed, as previously indicated, the irradiation aging tests performed on the ground in order to simulate the materials aging in orbit cannot be fully representative of the in-flight environment. In particular, the particle flux on the ground is highly accelerated compared to that in the space environment. In the first part of this paper, the experimental process is described with a presentation of the materials tested, the different irradiation conditions, and the associated analysis methods.

In the second part, a global synthesis on the flux effects observed on the different polymers tested is presented.

Finally, in the last part, a focus on the flux effects on silicone rubber is discussed.

\section{Materials and Experimental Methods}

\section{A. Materials}

Various polymers used on satellites were studied including surface materials, such as paints and coatings, and bulk materials, such as cables, fixing, and structural bonding.

The following surface materials that were of concern that were tested include room temperature vulcanized (RTV) silicone, polyurethane (PU), polyetherimide (PEI), and polyester film.

The investigated bulk materials were acrylic adhesive polyimide tape, RTV silicone, epoxy, fluorinated ethylene propylene (FEP), and acetal.

Two types of irradiations tests were performed depending on the function of the materials studied; surface materials were exposed to proton flux, and bulk materials were exposed to electron flux.

\section{B. Irradiations}

1. Proton Flux Irradiation

Proton irradiation was performed in the SEMIRAMIS facility (ONERA), using a $2.5 \mathrm{MeV}$ Van de Graff accelerator. The proton energy was $240 \mathrm{keV}$, and the total dose was $1 \times 10^{7} \mathrm{~Gy}$ (penetration at about $3 \mu \mathrm{m}$ ). Two different fluxes were selected: $8.7 \times 10^{9} p^{+}$. $\mathrm{cm}^{-2} \cdot \mathrm{s}^{-1}$ and $2.2 \times 10^{11} \mathrm{p}^{+} \cdot \mathrm{cm}^{-2} \cdot \mathrm{s}^{-1}$. A vacuum lower than $3 \times 10^{-7}$ mbar was obtained after a 1 day pump down period. The sample holder temperature was maintained at $25^{\circ} \mathrm{C}$ for the duration of the test.

\section{Electron Flux Irradiation}

The electron irradiation was performed by TRAD using a Van de Graff accelerator able to produce high-energy electrons (1-3 MeV).
A fixed electron current is delivered by the horn. The samples are horizontally disposed on the table. The dose rate is directly correlated to the average amount of electrons received by the samples under the beam.

The irradiation table is cooled down to $20^{\circ} \mathrm{C}$. A thermocouple is put on the table next to the samples, to check with a remote controller the eventual temperature increase during the experiment.

A display screen in the control room provides a direct view of the table and the samples.

The irradiation is performed under a nitrogen environment, thanks to a flowing nitrogen setup containing all the samples that are irradiated.

Before every irradiation, a preliminary dosimetry step is performed in order to determine the dose rate.

The dosimetry is performed using thin film radiachromic dosimeters at a given beam current and by measuring the deposited dose. The dose rate is calculated as the needed beam current to perform the irradiation at the target dose rate.

In the frame of this study, irradiations are performed at $3 \mathrm{MeV}$ and at standard and high dose rates, respectively, $5 \times 10^{11}$ and $7.4 \times 10^{12} e^{-} \cdot \mathrm{cm}^{-2} \cdot \mathrm{s}^{-1}$.

\section{Analysis Techniques}

1. Ultraviolet Visible Near-Infrared Spectroscopy

Different Ultraviolet-Visible-Near-Infrared (UV-Vis-NIR) analyses were performed at ONERA:

1) For measurements in air, the UV VIS NIR measurement system was composed of a Perkin Elmer Lambda 1050 spectrophotometer associated with a $150 \mathrm{~mm}$ diameter integrating sphere in air. The calibration was performed using a diffuser Spectralon SRS-99-010 standard. The diffuse transmission spectra in the range $200-2500 \mathrm{~nm}$ were acquired at intervals of $1 \mathrm{~nm}$, with the lamp change at $319.2 \mathrm{~nm}$.

2) For measurements under vacuum, the SEMIRAMIS facility is equipped with a Perkin Elmer Lambda 1050 spectrophotometer connected to a mobile integrating sphere under vacuum. Reflectance spectra in the range $250-2500 \mathrm{~nm}$ can be obtained, without breaking vacuum, before and after irradiation.

\section{X-Ray Photoelectron Spectroscopy}

Atomic concentration and chemical bonding information were obtained from the specimen surfaces by x-ray photoelectron spectroscopy (XPS). XPS measurements were realized with a Thermo Scientific $\mathrm{K}$ alpha spectrometer with a monochromated Al $\mathrm{K} \alpha$ radiation $(h \nu=1486.6 \mathrm{~V})$. Spectra were collected using an x-ray spot size of $400 \mu \mathrm{m}$.

\section{Attenuated Total Reflection Fourier Transform Infrared Spectroscopy}

Attenuated total reflection (ATR) Fourier transform infrared (FTIR) spectroscopy was performed at ONERA to characterize surface chemical degradations. The ATR FTIR spectra were recorded using a Nicolet 800 FT-IR spectrometer equipped with a deuterated triglyceride sulfate detector in the range $400-4000 \mathrm{~cm}^{-1}$, with a resolution of $4 \mathrm{~cm}^{-1}$. A diamond ATR accessory was used to investigate the first micrometers of the samples.

\section{Nuclear Magnetic Resonance Spectroscopy}

${ }^{29} \mathrm{Si}$ solid-state nuclear magnetic resonance spectra were recorded on a Brucker Avance 400 spectrometer equipped with a $4 \mathrm{~mm}$ probe operating at $9.39 \mathrm{MHz}$. Samples were spun at $12 \mathrm{kHz}$ at the magic angle using $\mathrm{ZrO}_{2}$ rotors. ${ }^{29} \mathrm{Si}$ Magic Angle Spinning (MAS) spectra were obtained under high-power proton decoupling conditions, with a small flip angle (30 deg) and a recycle delay of $60 \mathrm{~s}$.

\section{Differential Scanning Calorimetry}

At Thales Alenia Space, Differential Scanning Calorimetry (DSC) measurements were carried out using a NETZSCH DSC 204 apparatus for RTV silicone and a DSC823e from Mettler Toledo for other polymers. The ramp was fixed at $10^{\circ} \mathrm{C} / \mathrm{min}$. The analysis temperature range was fixed depending on polymer characteristics. 
Table 1 Flux effects on surface polymers

\begin{tabular}{|c|c|c|}
\hline & $1 \mathrm{Grad}\left(p^{+}\right)$ & $1 \mathrm{Grad}\left(p^{+}\right)$ \\
\hline Materials & $6 \times 10^{9}$ part $\cdot \mathrm{cm}^{-2} \cdot \mathrm{s}^{-1}$ & $2 \times 10^{11}$ part $\cdot \mathrm{cm}^{-2} \cdot \mathrm{s}^{-1}$ \\
\hline RTV silicone & \multicolumn{2}{|c|}{$\begin{array}{l}\text { 1) Increase of } \alpha_{s} \text {, decrease of stress at break and } \\
\text { modification of the polymer structure } \\
\text { 2) Higher degradation for High flux } \\
\text { 3) }\left(2 \times 10^{11} \text { part } \cdot \mathrm{cm}^{-2} \cdot \mathrm{s}^{-1}\right)(\text { developed in Sec. IV.A) }\end{array}$} \\
\hline PU & \multicolumn{2}{|c|}{$\begin{array}{l}\text { 1) No significant degradation (variation of } \alpha_{s}, \varepsilon_{\text {irr }} \text {, and } \\
\text { adherence test lower than the uncertainty of the } \\
\text { measurement) } \\
\text { 2) No flux significant impact }\end{array}$} \\
\hline PEI & \multicolumn{2}{|c|}{$\begin{array}{l}\text { 1) No significant degradation (variation of } \alpha_{s}, \varepsilon_{\text {irr }} \text { lower } \\
\text { than the uncertainty of the measurement) } \\
\text { 2) No flux significant impact }\end{array}$} \\
\hline
\end{tabular}

\section{Peel Test}

Peeling tests were performed in accordance with ASTM D1000 standard at Airbus Industries. Peelings were performed with a $180 \mathrm{deg}$ angle at $400 \mathrm{~mm} / \mathrm{min}$ and at ambient temperature on a Zwick Roell facility.

7. Adherence Test

Adherence tests performed on coatings according to ISO EN 2409. P224 tape was used at Airbus Industries.

8. Shear Test

Shear tests were performed according ISO specification (ISO.4587:2003). Tests were performed at room temperature on a Zwick Roell facility at Airbus Industries.

Shear Tests were performed on adhesives (epoxy and silicone) at Thales Alenia Space. Tests were performed at room temperature on a Zwick $100 \mathrm{kN}$ apparatus.

\section{Nanoindentation}

At Centre National d'Études Spatiales (CNES), nanoindentation was carried out with a nanoindenter AX (MTS), using a Berkovich point and a depth penetration of $5 \mu \mathrm{m}$. Twelve indentation points were performed on each sample. A sample Poisson ratio was fixed at 0.4 .

\section{Dynamic Mechanical Analysis}

Three-point flexure tests were performed on a Dynamic Mechanical Analysis (DMA) 242 NETZSCH at CNES. The temperature range of measurement was fixed according to polymer characteristics. Measurement was performed with a ramp of $5^{\circ} \mathrm{C} / \mathrm{min}$ and a frequency of $1 \mathrm{~Hz}$. The distortion amplitude was $30 \mu \mathrm{m}$, dynamic strength limit was fixed at $7.2 \mathrm{~N}$, and the constant part of static strength was fixed at $0 \mathrm{~N}$. Each sample was tested two or three times.

\section{Flux Effects on Polymers: General Results}

\section{A. Surface Irradiation}

Table 1 summarizes all the results obtained on surface materials during the aging tests.

No flux impact was evidenced except for RTV silicone. RTV silicone showed higher degradation at high proton flux.

\section{B. Bulk Irradiation}

Table 2 summarizes all the results obtained on bulk materials during the aging tests.

At this dose level and with the considered fluxes, no flux impact was evidenced except for RTV silicone, the second epoxy, and FEP. It has to be noted that in the same material family the degradation could be different (epoxy adhesive).
Table 2 Flux effects on bulk polymers

\begin{tabular}{|c|c|}
\hline & $500 \operatorname{Mrad}\left(e^{-}\right)$ \\
\hline Materials & $5 \times 10^{11}$ part $\cdot \mathrm{cm}^{-2} \cdot \mathrm{s}^{-1} 7 \times 10^{12}$ part $\cdot \mathrm{cm}^{-2} \cdot \mathrm{s}^{-1}$ \\
\hline Acrylic tape & $\begin{array}{l}\text { 1) High adherence degradation due to outgassing } \\
\text { under irradiation for high and low flux: bubble } \\
\text { creation (adherence test: }-95 \% \text { after irradiation) } \\
\text { 2) No significant flux effect at this dose level }\end{array}$ \\
\hline RTV silicone & $\begin{array}{l}\text { 1) Degradation of mechanical properties } \\
\text { 2) Increase of the thermo-optical properties: } \\
\text { yellowing (visual inspection) } \\
\text { 3) Higher degradation for low flux (developed in } \\
\text { Sec. IV.B) }\end{array}$ \\
\hline $\begin{array}{l}\text { 1st epoxy adhesive } \\
\text { bicomponent, } \\
\text { glass beads: } 1 \mathrm{wt} \%\end{array}$ & $\begin{array}{l}\text { 1) Low modification of mechanical properties } \\
\text { (stress at break: }-15 \% \text { after irradiation) even if } \\
\text { physicochemical property changes observed }\left[T_{g}\right. \\
\text { decrease }\left(-10^{\circ} \mathrm{C} \text { after irradiation) and observation of }\right. \\
\text { a new pic in ATR] } \\
\text { 2) No significant flux impact }\end{array}$ \\
\hline $\begin{array}{l}\text { 2nd Epoxy adhesive } \\
\text { bicomponent, } \\
\text { glass beads: } 12 \mathrm{wt} \%\end{array}$ & $\begin{array}{l}\text { 1) Degradation of mechanical properties (stress at } \\
\text { break: }-80 \% \text { after high flux, }-32 \% \text { after low flux) } \\
\text { 2) Physicochemical property changes ( } T_{g} \text { increase } \\
\left(+25^{\circ} \mathrm{C} \text { after high flux, unchanged after low flux), }\right. \\
\text { modification of the polymer structure with the } \\
\text { mobile chains removal) } \\
\text { 3) Degradation more important for the high-flux } \\
\text { irradiation }\end{array}$ \\
\hline FEP & $\begin{array}{l}\text { 1) Too important FEP properties degradation to } \\
\text { make characterizations. Only visual examination } \\
\text { 2) Degradation more important for the low-flux } \\
\text { irradiation }\end{array}$ \\
\hline Tefzel $^{\mathrm{TM}}$ & $\begin{array}{l}\text { 1) Degradation of mechanical properties (stress at } \\
\text { break: }-62 \% \text { after high flux, }-50 \% \text { under low flux). } \\
\text { 2) No significant impact of the irradiation flux }\end{array}$ \\
\hline Delrin ${ }^{\circledR}$ & $\begin{array}{l}\text { 1) Very strong degradation of the material at a dose } \\
\text { level of } 500 \text { Mrad } \\
\text { 2) No conclusion could be raised }\end{array}$ \\
\hline
\end{tabular}
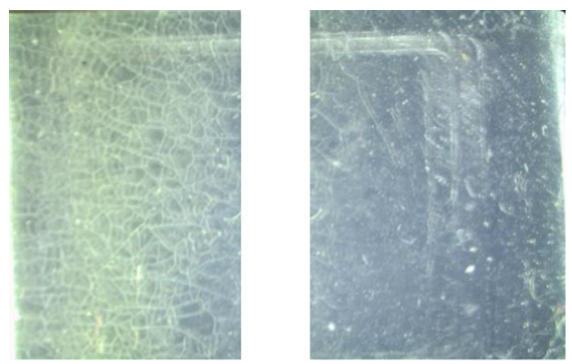

Fig. 1 Optical micrograph of the high-flux proton irradiated sample (cracks on the left side).

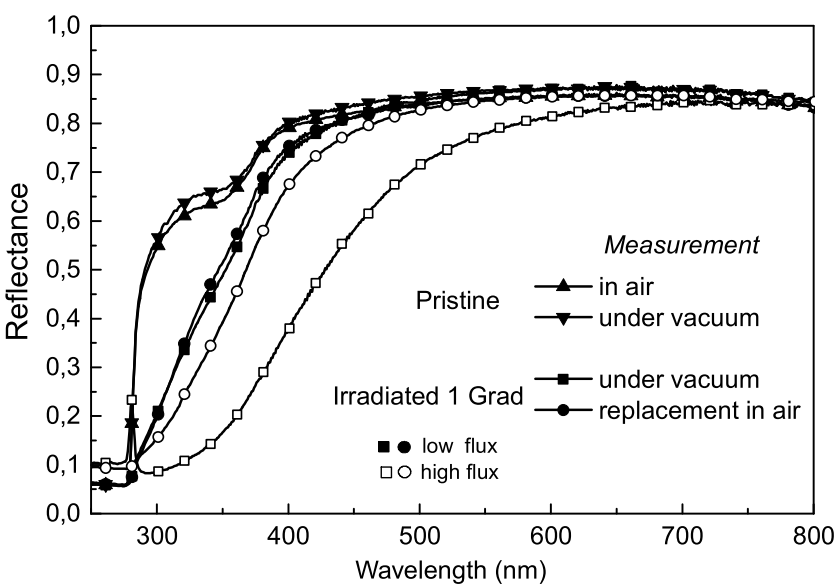

Fig. 2 Reflectance from 250 to $800 \mathrm{~nm}$ of pristine and protons irradiated silicone rubber. 
Table 3 Evolution of solar absorptance $\alpha_{s}$ at each step of proton irradiation

\begin{tabular}{lcccc}
\hline \hline & \multicolumn{2}{c}{ Pristine } & \multicolumn{2}{c}{ Irradiated 1 Grad } \\
\cline { 2 - 5 } \cline { 2 - 5 } Materials & In air & Under vacuum & Under vacuum & In air \\
\cline { 2 - 5 } & 0.19 & 0.18 & 0.20 & 0.21 \\
Low flux & 0.17 & 0.17 & 0.27 & 0.21 \\
High flux & 0.17 &
\end{tabular}

\section{Flux Effects on Silicone Rubbers}

To illustrate the process used and the results obtained in this study, particular attention is paid to the material considered as a surface and bulk sample during this testing: RTV silicone rubbers.

\section{A. Surface Irradiation}

A slight yellowing of samples was observed after proton irradiations. Moreover, inhomogeneous degradation on the high flux sample was noted, as shown on the optical micrograph (Fig. 1). An important surface damage was observed with the formation of many cracks localized in one-half of the sample. This phenomenon was previously observed on silicone under proton irradiation $[\underline{12}, 13]$.

\section{Thermo-Optical Properties}

The SEMIRAMIS facility enables measurement of thermo-optical properties in situ (under vacuum). Thermo-optical properties were measured by reflectance under air and vacuum conditions. Results are presented for the two different irradiation fluxes in Fig. 2.

A UV cutoff shift to higher wavelengths was observed under vacuum after irradiation, showing absorbent species formation. This shift is more important after the high flux irradiation. After the replacement of the samples under ambient air, new measurements showed that there were recoveries of their reflectance spectra. This recovery had been previously observed on different materials $[14,15]$. This phenomenon is particularly significant for the high flux irradiated sample. The low and high flux final spectra (measurement in air) were closed.

Thermo-optical coefficients (IR emissivity and solar absorptances) have been calculated. IR emissivity changes were not significant. Solar absorptances are reported in Table $\underline{3}$.

Recovery phenomenon was also observed in the change in $\alpha_{s}$, particularly for the high-flux irradiated sample. Accordingly, the $\alpha_{s}$ end of test values (measurement in the air environment) for both aged samples were similar, even though the interim $\alpha_{s}$ (measurement under vacuum just after irradiation) was higher when proton flux was higher.

\section{X-Ray Photoelectron Spectroscopy}

XPS measurements show that the atomic percentages obtained for the different samples are similar $(\mathrm{C}, \mathrm{O}$, and $\mathrm{Si})$. However, a shoulder corresponding to the $\mathrm{SIO}_{x>3}$ bond is observed for irradiated samples. This is more evident for the high-flux sample (Fig. 3). This result indicates an evolution of the surface nature of the silicone rubbers into silica, which is a function of the total dose and the irradiation flux.

3. Attenuation Total Reflection Fourier Transform Infrared Spectroscopy ATR FTIR spectra obtained before and after proton irradiation are presented in Fig. 4.

A distinction can be seen on the ATR FTIR measurements between the high-flux cracked sample and the other irradiated samples (lowand high-flux noncracked):

1) For the high-flux cracked sample, ATR FTIR measurement confirms silica formation on the high-flux irradiated sample, with an increase of the $\mathrm{SiOH}$ bands absorption $\left(3100-3600 \mathrm{~cm}^{-1}\right)[16,17]$. The appearance of a new absorption band $\left(1700 \mathrm{~cm}^{-1}\right)$, attributed to the $\mathrm{CO}$ groups, responsible for the sample yellowing, is also observed.

2) For the other irradiated samples, spectra obtained after irradiation are closer to that of the pristine sample. However, an increase of the $\mathrm{SiH}$ and a decrease of the $\mathrm{SiCH} 3$ and SiPhenyl groups are observed. A SiOSi characteristic peak $\left(1070 \mathrm{~cm}^{-1}\right)$ decreases after irradiation, for both high-flux irradiated samples, while it is unchanged for the low-flux irradiated sample.

The formation of a silica-type layer localized on the surface can explain why cracks appear: the density of silica is higher than that of silicone rubber.

4. ${ }^{29} \mathrm{Si}$ Solid-State Nuclear Magnetic Resonance Spectroscopy

${ }^{29} \mathrm{Si}$ solid-state nuclear magnetic resonance (NMR) spectra of all silicone rubber samples are presented in Fig. 5 ( $e^{-}$and $p^{+}$irradiation).

Pristine and irradiated spectra show a high signal at $-22 \mathrm{ppm}$ attributed to $D$ siloxane units within the chain. Considering proton irradiation, a slight peak corresponding to $\mathrm{SiCH}_{2} \mathrm{Si}$ bonds appears

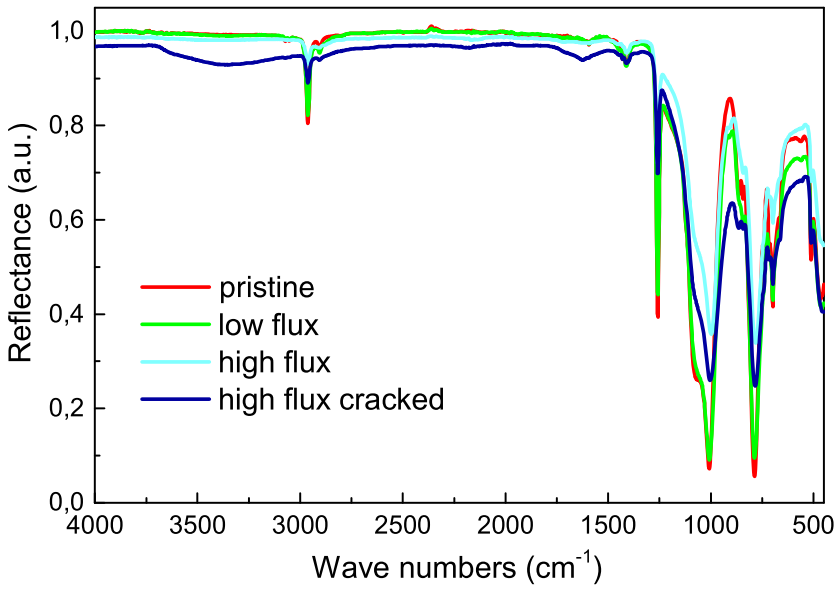

Fig. 4 ATR FTIR silicone rubber before and after proton irradiation.

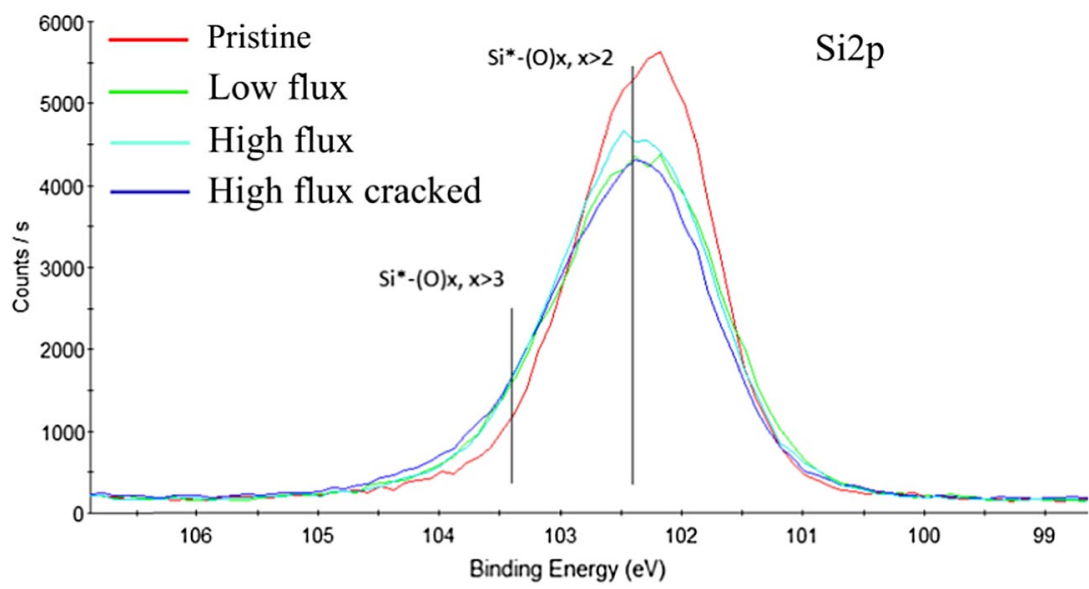

Fig. 3 XPS spectra of silicone rubber before and after proton irradiation. 


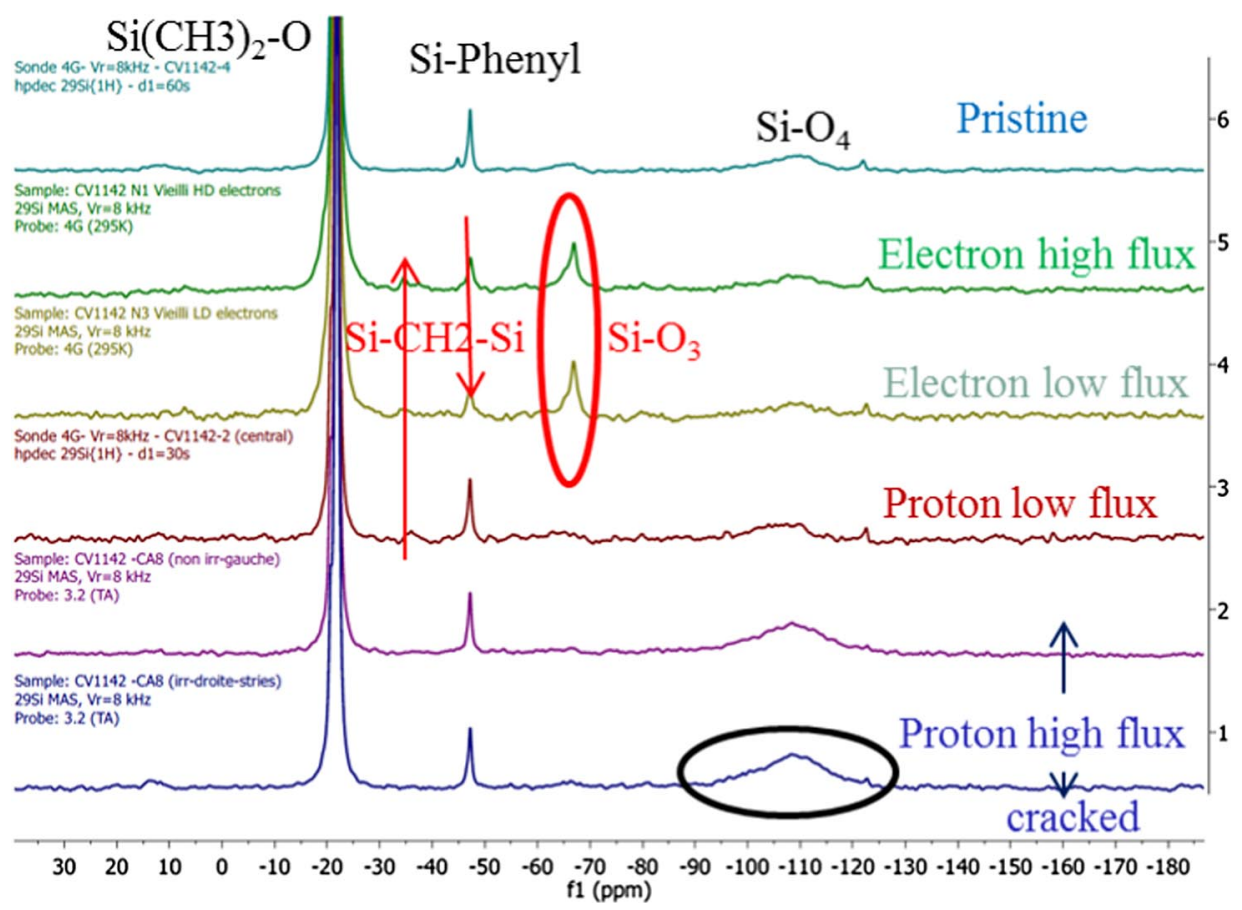

Fig. $5{ }^{29} \mathrm{Si}$ NMR spectra of silicone rubber before and after electron and proton irradiation.

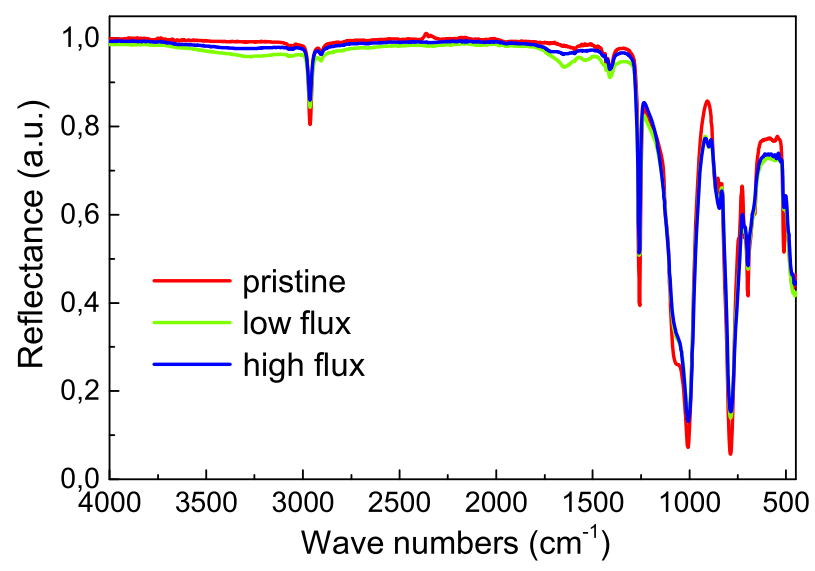

Fig. 6 ATR FTIR silicone rubber before and after electron irradiation. after low-flux irradiation $(-37 \mathrm{ppm})$. This phenomenon indicates new crosslinks. An increase of the $\mathrm{SiO}_{4}$ broad signal $(-110 \mathrm{ppm})$ is observed after the high-flux irradiation, particularly into the cracked zone. This indicates the creation of silica during proton high-flux irradiation.

\section{B. Bulk Irradiation}

To assess the bulk properties of the material, different characterization techniques were used such as UV VIS NIR spectroscopy, NMR, DMA, nanoindentation, and DSC to determine the evolution of the physicochemical properties of the material submitted to the electron beam.

The ATR FTIR spectroscopy shows a significant degradation of the samples submitted to a standard dose rate, leading to the apparition of $\mathrm{SiOH}, \mathrm{CO}$, and $\mathrm{SiH}$ bonds. For high dose rate, the sample modification consists mainly in the creation of $\mathrm{SiH}$ bonds and on the decrease of the number of SiPhenyl bonds (Fig. 6).
$E^{\prime} M P a$

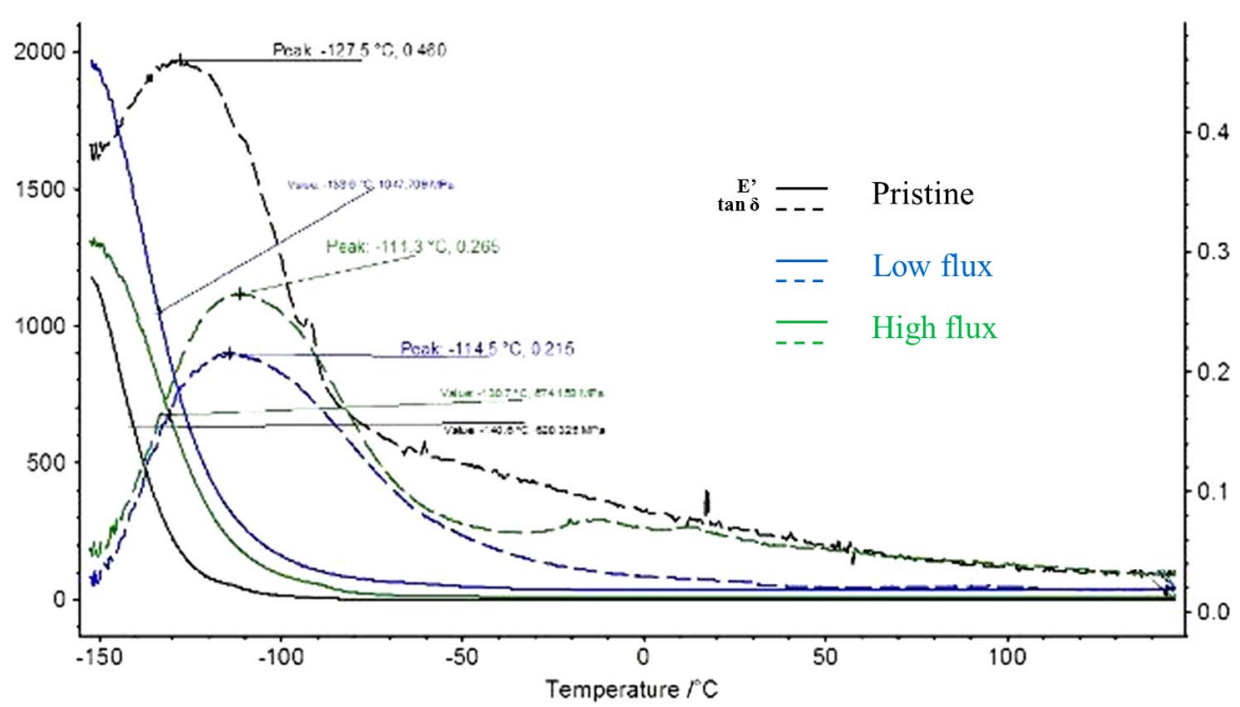

Fig. 7 DMA spectra of silicone rubber before and after electron irradiations. 
This tendency is confirmed by the NMR analysis, which reveals the formation of crossing points $\left(\mathrm{SiO}_{3}\right.$ bonds) coupled with the diminution of the SiPhenyl bonds (Fig. 5). After irradiation at the standard dose rate only, another type of crossing point is also observed $\left(\mathrm{SiCH}_{2} \mathrm{Si}\right)$.

Complementary NMR analysis shows a stiffening of the silicone skeleton after electron irradiation.

The DMA tests focused on the mechanical behavior of the material depending on the temperature (Fig. 7). Results show an evolution of the temperature of the inflexion point for the storage modulus, with a decrease of about $10^{\circ} \mathrm{C}$ after electron irradiation. Additionally, no significant difference was noticed between the values after standard and high dose rate irradiation.

DSC analysis was also performed. The results reveal that the material was not fully polymerized, leading to the apparition of an exothermic peak during the first scan. These peaks were localized at -118 and $-100^{\circ} \mathrm{C}$ for pristine and high dose rate irradiated samples, respectively. It can be noted that such a peak was not observed for the sample irradiated at the standard dose rate. The evolution of the $T_{g}$ was also monitored. Its value was measured at $-110,-103$, and $-104^{\circ} \mathrm{C}$, respectively, for one pristine sample, the one irradiated at the standard dose rate and the one submitted to a high dose rate. Thus, there was an evolution of this temperature after irradiation, but no effect of the dose rate was noticed.

Finally, mechanical properties of the material were assessed through the irradiation of shear test samples. A clear decrease of the tensile strength of around $40 \%$ was measured, from 4.1 to $2.3 \mathrm{MPa}$. The samples irradiated at the standard dose rate seemed slightly more degraded.

\section{Conclusions}

Different materials families were tested in the frame of this study. They were selected to represent some of the main organic material families used on spacecraft such as epoxies, silicones, polyurethanes, fluoropolymers, etc.

The aim of this study was to determine the influence of the irradiation flux on material degradation. It has to be noticed that, due to facility limitations, the flux as applied in the frame of this study, even the lowest ones, was still largely above real fluxes in orbit.

During this study, various analysis tests were performed on the materials in order to be able to determine the evolution of the functional properties of the tested materials but also to determine some physicochemical changes.

The general following observations can be reported:

1) There is no evidence of a similar effect of the irradiation flux on the different materials families. Indeed, for some materials families, the degradation is higher with a higher irradiation flux, while it could be the contrary for another material family.

2) The effects can also be different for two materials in the same family (different behavior observed on two epoxies).

3) The irradiation flux effect can be different on the same material depending on the type of particle irradiation (electrons or protons).

This study demonstrated that ground-testing parameters are important to the evaluation of material behavior against radiation. The current study focused on the irradiation flux effect. The investigation of other irradiation parameters such as the type of particles, the atmosphere, and the irradiation temperature is also relevant and will be investigated in future work.

\section{References}

[1] Kinderman, E. M., and Radding, S. B., "Nuclear Radiation Effects on Structural Plastics and Adhesives," Armed Services Technical Information Agency, ASTIA Document, AD 130837, 1957.
[2] Tavlet, M., Fontaine, A., and Schönbacher, H., "Compilation of Radiation Damage Test Data Part II," Conseil européen pour la recherche nucléaire CERN Paper 98-01, 1998.

[3] Tighe, A. P., "Space Environment Simulation and Materials Testing," Encyclopedia of Aerospace Engineering, John Wiley \& Sons, Ltd., 2010, pp. 1-13. doi: $10.1002 / 9780470686652$

[4] "Space Systems, Space Environment, Simulation Guidelines for Radiation Exposure of Non-Metallic Materials," ISO 15856:2010, Geneva, CH, 2010.

[5] "Standard Practice for Combined, Simulated Space Environment Testing of Thermal Control Materials with Electromagnetic and Particulate Radiation," ASTM E512-94, ASTM International, West Conshohocken, PA, 2010.

[6] "Space Product Assurance Particle and UV Radiation Testing for Space Materials," ESA, ECSS-Q-ST- 70-06C, Noordwijk, The Netherlands, 2008.

[7] Tavlet, M., and Ilie, S., "Behaviour of Organic Materials in Radiation Environment," 5th European Conference on Radiation and Its Effects on Components and Systems, RADECS, Vol. 99, IEEE, 1999, pp. 210 215.

[8] Gillen, K. T., and Clough, R. L., "Time-Temperature-Dose Rate Superposition: A Methodology for Extrapolating Accelerated Radiation Aging Data to Low Dose Rate Conditions," Polymer Degradation and Stability, Vol. 24, No. 2, Jan. 1989, pp. 137-168.

doi:10.1016/0141-3910(89)90108-0

[9] Wilski, H., "The Radiation Induced Degradation of Polymers," International Journal of Radiation Applications and Instrumentation, Part C: Radiation Physics and Chemistry, Vol. 29, No. 1, Jan. 1987, pp. 1-14. doi:10.1016/1359-0197(87)90054-3

[10] Briskman, B. A., Klinshpont, E. R., Stepanov, V. F., and Tlebaev, K. B., "Determination of Dose Rate Effects in Polymers Irradiated in Vacuum," Journal of Spacecraft and Rockets, Vol. 41, No. 3, 2004, pp. 360-365. doi: $10.2514 / 1.10891$

[11] Hardgrove, W. R., "Space Simulation Test for Thermal Control Materials," 16th Space Simulation Conference Confirming Spaceworthiness into the Next Millennium, NASA, 1991, pp. 267-285.

[12] Jochem, H., Rejsek-Riba, V., Maerten, E., Remaury, S., Solé, S., Sierra, G., Baceiredo, A., and Guillaumon, O., "Effects of $400 \mathrm{keV}$ Electrons Flux on Two Space Grade Silicone Rubbers," Materials Chemistry and Physics, Vol. 141, No. 1, Aug. 2013, pp. 189-194. doi:10.1016/j.matchemphys.2013.05.002

[13] Jochem, H., Rejsek-Riba, V., Maerten, E., Baceiredo, A., Remaury, S., and Solé, S., "Effects of Electron and Proton Flux on the Chemical Structure of a Silicone Rubber," Proceddings of ISMSE-12 12th International Symposium on Materials in the Space Environment [CDROM], edited by Ouwehand, L., ESA Communications, ESTEC SP705, Noordwijk, Feb. 2013.

[14] Kiefer, R. L., and Orwoll, R. A., "Space Environment Effects on Polymeric Materials," NASA CR-184648, 1988, http://ntrs.nasa.gov/ search.jsp?R=19890005884.

[15] Marco, J., Remaury, S., and Tonon, C., "Eight Years GEO Ground Testing of Thermal Control Coatings," Proceddings of ISMSE-11 11th International Symposium on Materials in the Space Environment [CDROM], CNES / Centre National Etudes Spatiales, Toulouse, 2009, http:// esmat.esa.int//Materials_News/ISME09/cd_isme09.pdf.

[16] Zhang, L. X., He, S. Y., Xu, Z., and Wei, Q., "Damage Effects and Mechanisms of Proton Irradiation on Methyl Silicone Rubber," Materials Chemistry and Physics, Vol. 83, Nos. 2-3, Feb. 2004, pp. 255-259. doi:10.1016/j.matchemphys.2003.09.043

[17] Tomozawa, M., Hong, J. -W., and Ryu, S.-R., "Infrared (IR) Investigation of the Structural Changes of Silica Glasses with Fictive Temperature," Journal of Non-Crystalline Solids, Vol. 351, Nos. 12-13, May 2005, pp. 1054-1060.

doi:10.1016/j.jnoncrysol.2005.01.017
T. K. Minton Associate Editor 